\title{
Customer Satisfaction Evaluation of Third Party Logistics Based on Fuzzy Comprehensive Evaluation Method
}

\author{
Liu Aolin \\ School of Management, Wuhan University of Technology, Wuhan, P. R. China, 430000
}

(E-mail: 494018558@qq.com )

\begin{abstract}
The third party logistics is a new service business, its customer satisfaction level directly affects the customers' purchase decisions, which also determines the enterprises' market share, therefore, the evaluation and analysis of the customer satisfaction are of great importance to the third party logistics enterprises. This paper explains the research status quo of the customer satisfaction of the third party logistics, and combines the current development situation of the third party logistics enterprises, using fuzzy comprehensive evaluation and combining the questionnaire to carry on a simple appraisal and analysis of the results for one third party logistics enterprise.
\end{abstract}

Keywords: The third party logistics; customer satisfaction level; fuzzy comprehensive evaluation

\section{Introduction}

With the development of the world economy integration as well as science and technology, consumer spending are increasingly diverse, and personalized. The main factors that influence customer purchasing decisions are services when purchasing commodity, in addition to the quality of the goods. Customer services occupy a very important position in the purchase decision (John T Mentzer et al.2012)[1]. In this case, more and more enterprises have begun to focus on customer service, and think customer service is very important factor of corporate competitiveness. In particular with the application of information technology and the internet, competition among enterprises has gone beyond the geographical limitations, the center of competition evolved to logistics services competition. In order to improve the quality of logistics services, more and more companies are starting to outsource their logistics services to the specialized third-party logistics enterprises, thereby promoting the rapid development of the third party logistics industry (Lisa.2011)[2]. In such a competitive market environment, and how to provide the customers with high standards and comprehensive, integrated logistics services, improve customer satisfaction and gain customer loyalty, became key to the survival and development of third party logistics enterprise.

\section{Literature review}

In early time, Mentzer, from marketing perspective and based on logistics customer satisfaction, proposed with time, accessibility and quality to measure the quality of entity distribution service, and expanded logistics service quality of evaluation index to nine in 2010, specially including personnel communication quality, orders release quality, information quality, ordered process, commodity precision rate, commodity intact degree, commodity quality, errors processing and time. Qiuxiang Yi and Aifeng Yang (2015) [3]made a empirical research for the influence factors of customer satisfaction studies in third party logstics in use of importance-satisfaction analysis. Anil Jindal and Kuldip Singh Sangwan (2013) [4]quantified small sample system that known about information unsecurity based on grey relevancy theory and AHP method, quantified indicators, an evaluated the customer satisfaction of three third-party logistics enterprises. Chen-no Wang (2010) [5]put forward the evaluation index system of logistics service 
quality in China based on the empirical service, according to the characteristics of logistics service. This evaluation index system includes seven dimension, which are time quality,communication quality, order completion quality, error handling quality, intact quality, flexibility and convenience of products. Socrates J (2012) [6]eatablished TPL evaluation index system of customer satisfaction, using the integrated grey and TOPSIS method to evaluate customer satisfaction of third party logistics. From the customers point of view, Chen (2012) [7]established the evaluation system of logistics service quality using dynamic fuzzy comprehensive evaluation method. This system includes five first order index: reliability, assurance, responsiveness, empathy and perception indicator, and 16 secondary indexes.

This study summarizes previous studies on customer satisfaction research, and combines the particularities of the third party logistics customer satisfaction, builds customer satisfaction evaluation index system for third-party logistics, besides, using fuzzy comprehensive evaluation on the evaluation of a third-party logistics enterprise.

\section{Method}

\subsection{The principle of establishing the index system}

The third-party logistics customer satisfaction evaluation has a certain ambiguity.

It is a complex process that involves both qualitative factors and theorems. The establishment and evaluation of index system should follow principles blow: First, scientific principles, that is the establishment of index system must be integral, and the index should has must of logic relationship with each other; Second, representative principles, that is the index system should select principles strong of representative; Third, feasibility principles, that is the establishment of index system should meet objective reality, data should be easily collected and easy operation; Fourth, general principles, that is the established index system of customer satisfaction should has widely of applicability (Huimin Xiao.2010)[8].

\subsection{The establishment of the index system}

The application of customer satisfaction theory in third party logistics is different with general products and service. It has following particularity: First, the customer of third-party logistics is enterprise, but not personal; Second, third-party logistics is a typical of service industry, it has the features of service industry; Besides, third-party logistics is kind of management activities which constitute transport, warehousing, and a series of logistics activities (Sharif.2012)[9].Thus, compared with general activities, we should make it easy quantitative processing, enhance the scientificity and objectivity of evaluation models when building third-party logistics index system.

This paper summarizes previous theory about customer satisfaction of third-party logistics model, combined with the characteristics of the third party logistics industry, and puts forward the customer satisfaction evaluation index system in third-party logistics, as shown in table 1.

Table 1 The customer satisfaction evaluation index system in third party logistics

\begin{tabular}{|c|c|}
\hline Level indicators & Secondary indexes \\
\hline \multirow{4}{*}{ Logistics enterprise image $u_{1}$} & Logistics facilities and equipment $u_{11}$ \\
\cline { 2 - 2 } & Progressiveness of information system $u_{12}$ \\
\cline { 2 - 2 } & Brand image $u_{13}$ \\
\cline { 2 - 2 } & Corporate reputation $u_{14}$ \\
\cline { 2 - 2 } Price of logistics service $u_{2}$ & The quality of staff $u_{15}$ \\
\cline { 2 - 2 } & Total price satisfaction $u_{21}$ \\
\hline \multirow{2}{*}{ Price/performance $u_{22}$} \\
\hline
\end{tabular}


Table 1, cont.

\begin{tabular}{|c|c|}
\hline Level indicators & Secondary indexes \\
\hline Price of logistics service $u_{2}$ & Comparing with the prices of similar enterprises $u_{23}$ \\
\hline \multirow{4}{*}{ Logistics service quality $u_{3}$} & On time delivery rate $u_{31}$ \\
\cline { 2 - 2 } & The damage rate $u_{32}$ \\
\cline { 2 - 2 } & Good of information communication $u_{33}$ \\
\cline { 2 - 2 } & Specialization of services $u_{34}$ \\
\cline { 2 - 2 } & Rapid response capacity $u_{35}$ \\
\hline \multirow{4}{*}{ Customer complaint $u_{4}$} & Service personalization $u_{36}$ \\
\cline { 2 - 2 } & Complaint channel accessibility $u_{41}$ \\
\cline { 2 - 2 } & The timeliness of solving complaint $u_{42}$ \\
\hline \multirow{4}{*}{ Customer loyalty $u_{5}$} & Satisfaction of solution results $u_{43}$ \\
\hline \multirow{4}{*}{} & Possibility of purchase again $u_{51}$ \\
\cline { 2 - 2 } & The possibility of recommending $u_{52}$ \\
\cline { 2 - 2 } & The maximum of receiving the price increase $u_{53}$ \\
\cline { 2 - 2 } & Possibility of establishing a partnership $u_{54}$ \\
\hline
\end{tabular}

3.3 The fuzzy comprehensive evaluation model of customer satisfaction in third-party logistics

Because customer satisfaction is a state of mind and experience with a strong ambiguity, and the indicators used to measure customer satisfaction are fuzzy, so the measurement of customer satisfaction by fuzzy synthetic evaluation method is more appropriate.

(1) Determining the evaluation factors set

In this article, the factor set is divided into two floors. The first layer is $U=\left\{u_{1}, u_{2}, u_{3}, u_{4}, u_{5}\right\}$; The second layer are:

$u_{1}=\left\{u_{11}, u_{12}, u_{13}, u_{14}, u_{15}\right\}, u_{2}=\left\{u_{21}, u_{22}, u_{23}\right\}, u_{3}=\left\{u_{31}, u_{32}, u_{33}, u_{34}, u_{35}, u_{36}\right\} u_{4}=\left\{u_{41}, u_{42}, u_{43}\right\}, u_{5}=\left\{u_{51}, u_{52}, u_{53}, u_{54}\right\}$, as shown in table 1 .

(2) the comments set of the evaluation criteria

To make comments set by the various general evalution results came from reviewers $V=\left\{v_{1}, v_{2}, v_{3}, v_{4}, v_{5}\right\}$.Among them, $v_{1}$ expresses strong dissatisfied, $v_{2}$ expresses not satisfation, $v_{3}$ expresses general satisfaction, $v_{4}$ expresses satisfaction, $v_{5}$ expresses great satisfaction. The ultimate aim of the fuzzy comprehensive evaluation is to drawe a best result from the comments set,taking all factors into account.

(3) Determining the weight of each index

This paper uses the analytic hierarchy process (AHP) to determine the weight, and determines matrix elements by the expert evaluating method, then test the consistency and get weight.

(4) Constructing evaluation membership matrix

First of all, evaluating from a single factor among factors set, determine the scores of objects in various targets $r_{i p}=\left\{r_{i p 1}, r_{i p 2}, r_{i p 3}, r_{i p 4}, r_{i p 5}\right\}$, among them, $r_{i p j}$ expresses the degree of evaluation object under the first level(i) and at the second level(p) to the level $v_{j}$. Then $r_{i p}$ is a line of single factor fuzzy evaluation matrix:

$$
R_{i}=\left[\begin{array}{lllll}
r_{i 11} & r_{i 12} & r_{i 13} & r_{i 14} & r_{i 15} \\
r_{i 21} & r_{i 22} & r_{i 23} & r_{i 24} & r_{i 25} \\
& & & & \\
r_{i p 1} & r_{i p 2} & r_{i p 3} & r_{i p 4} & r_{i p 5}
\end{array}\right]
$$


Where $\mathrm{P}$ is the number of elements on factor $\operatorname{set}\left(u_{i}\right)$, that is number of secondary level indicators under level indicators(i).

(5) The fuzzy comprehensive evaluation

Evaluating matrix $(\mathrm{R})$ fuzzily by weights(W) from step three and the single factor from step four.Calculating the set of evaluation using fuzzy comprehensive evaluation $B=W \quad R$.We take weighted-average $M(\bullet,+)$ here.This model takes all factors of influence into account when evaluating the level of membership of level $v_{j}$.

\section{Empirical analysis}

(1) determine the weight of factors

To one of the third party logistics enterprise's customer satisfaction evaluation, using expert evaluating method to give each factor a score, constructing judgement matrix. Taking following customer satisfaction level indicator matrix as an example,as shown in table 2.

Table 2 Level indicator matrix

\begin{tabular}{|c|c|c|c|c|c|}
\hline & $\begin{array}{c}\text { Logistics } \\
\text { corporate } \\
\text { image } u_{1}\end{array}$ & $\begin{array}{c}\text { Price of } \\
\text { logistics } \\
\text { service } u_{2}\end{array}$ & $\begin{array}{c}\text { Logistics } \\
\text { service } \\
\text { quality } u_{3}\end{array}$ & $\begin{array}{c}\text { Customer } \\
\text { complaint } u_{4}\end{array}$ & $\begin{array}{c}\text { Customer } \\
\text { loyalty } u_{5}\end{array}$ \\
\hline Logistics corporate image $u_{1}$ & 1 & $1 / 6$ & $1 / 5$ & $1 / 3$ & 1 \\
\hline Price of logistics service $u_{2}$ & 6 & 1 & 2 & 3 & 6 \\
\hline Logistics service quality $u_{3}$ & 5 & $1 / 2$ & 1 & 2 & 5 \\
\hline Customer complaint $u_{4}$ & 3 & $1 / 3$ & $1 / 2$ & 1 & 3 \\
\hline Customer loyalty $u_{5}$ & 1 & $1 / 6$ & $1 / 5$ & $1 / 3$ & 1 \\
\hline
\end{tabular}

In this article, we calculate the largest eigenvalue based on the above data using MATLAB software $\lambda=5.0401$. The corresponding feature vector $W=\left[\begin{array}{lllll}0.0604 & 0.4353 & 0.2828 & 0.1611 & 0.0604\end{array}\right]$ $C I=0.01, C R=C I / R I=0.009<0.01$,so it conforms consistency inspection.

We put forward the weight vector directly becouse of too many iudgement matrix of secondary indicators. As shown in table 3.

Table 3 Weight table

\begin{tabular}{|l|c|}
\hline Level indicators & Secondary indexes \\
\hline \multirow{4}{*}{ Logistics enterprise image $u_{1}(0.0604)$} & Logistics facilities and equipment $u_{11}(0.173)$ \\
\cline { 2 - 2 } & Progressiveness of information system $u_{12}(0.165)$ \\
\cline { 2 - 2 } & Brand image $u_{13}(0.438)$ \\
\cline { 2 - 2 } Price of logistics service $u_{2}(0.4353)$ & Corporate reputation $u_{14}(0.1530)$ \\
\cline { 2 - 2 } & The quality of staff $u_{15}(0.058)$ \\
\cline { 2 - 2 } & Total price satisfaction $u_{21}(0.226)$ \\
\cline { 2 - 2 } & Comparing with the prices of similar enterprises $u_{23}(0.422)$ \\
\hline
\end{tabular}

That is the level index weight $W=\left[\begin{array}{lllll}0.0604 & 0.4353 & 0.2828 & 0.1611 & 0.0604\end{array}\right]$, the Secondary indicators weight:

$W_{1}=\left[\begin{array}{lllll}0.173 & 0.165 & 0.224 & 0.243 & 0.195\end{array}\right], \quad W_{2}=\left[\begin{array}{llll}0.226 & 0.352 & 0.422\end{array}\right] \quad, \quad W_{3}=\left[\begin{array}{llllll}0.189 & 0.271 & 0.112 & 0.204 & 0.142 & 0.082\end{array}\right]$, $W_{4}=\left[\begin{array}{lll}0.223 & 0.354 & 0.423\end{array}\right], \quad W_{5}=\left[\begin{array}{llll}0.142 & 0.362 & 0.345 & 0.151\end{array}\right]$

(2) Determining evaluation membership matrix

This paper take questionnaire approach to collect data and process the data matrix. In this study, the matrix element represents a set of indicators'score to achieve the rating questionnaire make up 
the score of the questionnaire. Questionnaire data was normalized and get the membership matrix secondary indicators:

$$
\begin{aligned}
& R_{1}=\left[\begin{array}{ccccc}
0 & 0 & 0.44 & 0.38 & 0.18 \\
0 & 0.03 & 0.66 & 0.25 & 0.06 \\
0 & 0 & 0.43 & 0.37 & 0.20 \\
0 & 0 & 0.48 & 0.38 & 0.14 \\
0 & 0.08 & 0.59 & 0.31 & 0.02
\end{array}\right] \quad R_{2}=\left[\begin{array}{ccccc}
0 & 0.06 & 0.48 & 0.33 & 0.13 \\
0.02 & 0.04 & 0.33 & 0.48 & 0.13 \\
0.02 & 0.03 & 0.34 & 0.5 & 0.11
\end{array}\right] \quad R_{3}=\left[\begin{array}{ccccc}
0.02 & 0.07 & 0.47 & 0.34 & 0.1 \\
0.03 & 0.08 & 0.46 & 0.4 & 0.03 \\
0.02 & 0.13 & 0.58 & 0.19 & 0.08 \\
0 & 0.09 & 0.42 & 0.4 & 0.09 \\
0 & 0.13 & 0.54 & 0.23 & 0.1 \\
0 & 0.23 & 0.48 & 0.24 & 0.05
\end{array}\right] \\
& R_{4}=\left[\begin{array}{ccccc}
0.03 & 0.27 & 0.46 & 0.15 & 0.09 \\
0.04 & 0.27 & 0.44 & 0.21 & 0.04 \\
0 & 0.15 & 0.47 & 0.24 & 0.14
\end{array}\right] \quad R_{5}=\left[\begin{array}{ccccc}
0 & 0.06 & 0.57 & 0.33 & 0.04 \\
0 & 0.12 & 0.42 & 0.44 & 0.02 \\
0.06 & 0.29 & 0.59 & 0.06 & 0 \\
0 & 0.08 & 0.46 & 0.33 & 0.13
\end{array}\right]
\end{aligned}
$$

(3) the fuzzy comprehensive evaluation

Based on the above evaluation of the construction of the membership matrix and corresponding weights, calculate the rating level indicator vectors:

$$
\begin{aligned}
& B_{1}=W_{1} \quad R_{1}=\left[\begin{array}{lllll}
0.173 & 0.165 & 0.224 & 0.243 & 0.195
\end{array}\right]\left[\begin{array}{ccccc}
0 & 0 & 0.44 & 0.38 & 0.18 \\
0 & 0.03 & 0.66 & 0.25 & 0.06 \\
0 & 0 & 0.43 & 0.37 & 0.20 \\
0 & 0 & 0.48 & 0.38 & 0.14 \\
0 & 0.08 & 0.59 & 0.31 & 0.02
\end{array}\right] \\
& =\left[\begin{array}{lllll}
0 & 0.021 & 0.513 & 0.342 & 0.124
\end{array}\right] \\
& B_{2}=\left[\begin{array}{lllll}
0.016 & 0.04 & 0.368 & 0.455 & 0.121
\end{array}\right] \quad B_{3}=\left[\begin{array}{llllll}
0.014 & 0.105 & 0.480 & 0.328 & 0.073
\end{array}\right] \\
& B_{4}=\left[\begin{array}{lllll}
0.021 & 0.219 & 0.457 & 0.209 & 0.094
\end{array}\right] \quad B_{5}=\left[\begin{array}{lllll}
0.021 & 0.164 & 0.506 & 0.276 & 0.033
\end{array}\right]
\end{aligned}
$$

So the membership matrix of fuzzy evaluation of the level indicator is obtained:

$$
R=\left[\begin{array}{l}
B_{1} \\
B_{2} \\
B_{3} \\
B_{4} \\
B_{5}
\end{array}\right]=\left[\begin{array}{ccccc}
0 & 0.021 & 0.513 & 0.342 & 0.124 \\
0.016 & 0.04 & 0.368 & 0.455 & 0.121 \\
0.014 & 0.105 & 0.480 & 0.328 & 0.073 \\
0.021 & 0.219 & 0.457 & 0.209 & 0.094 \\
0.021 & 0.164 & 0.506 & 0.276 & 0.033
\end{array}\right]
$$

Finally,calculating the evaluation vector of cunstomer satisfaction degree:

$$
\begin{aligned}
& B=W \\
& B=\left[\begin{array}{lllll}
0.0604 & 0.4353 & 0.2828 & 0.1611 & 0.0604
\end{array}\right]\left[\begin{array}{cccccc}
0 & 0.021 & 0.513 & 0.342 & 0.124 \\
0.016 & 0.04 & 0.368 & 0.455 & 0.121 \\
0.014 & 0.105 & 0.480 & 0.328 & 0.073 \\
0.021 & 0.219 & 0.457 & 0.209 & 0.094 \\
0.021 & 0.164 & 0.506 & 0.276 & 0.033
\end{array}\right] \\
& =\left[\begin{array}{lllll}
0.015 & 0.094 & 0.431 & 0.360 & 0.1
\end{array}\right]
\end{aligned}
$$

According to vector of fuzzy evaluation of customer satisfaction results, we find that 1.5 percnt of customers are strong dissatisfied with the logistics service provided by this logistics company, and 9.4 percent of customers are not satisfied, 43.1 percent are general satisfied, 36 percent of them are satisfied,and only 1 percent of people are strong satisfied.

The quantitative score for each element of the set are $v_{1}=40, v_{2}=55, v_{3}=70, v_{4}=85$, $v_{5}=100$.The closer to 100 , the satisfaction are higher.So we can calculate the score of each level and the final total score. As shown in table 4. 
Table 4 Evaluation results of a logistics company customer satisfaction

\begin{tabular}{|c|c|c|c|c|c|c|c|}
\hline Level indicators & weights & $\begin{array}{c}\text { Strong } \\
\text { dissatisfied }\end{array}$ & dissatisfied & $\begin{array}{c}\text { General } \\
\text { satisfied }\end{array}$ & satisfied & $\begin{array}{c}\text { Strong } \\
\text { satisfied }\end{array}$ & score \\
\hline $\begin{array}{c}\text { Logistics enterprise } \\
\text { image }\end{array}$ & 0.0604 & 0 & 0.021 & 0.513 & 0.342 & 0.124 & 78.54 \\
\hline $\begin{array}{c}\text { Price of logistics } \\
\text { service }\end{array}$ & 0.4353 & 0.016 & 0.04 & 0.368 & 0.455 & 0.121 & 79.38 \\
\hline $\begin{array}{c}\text { Logistics service } \\
\text { quality }\end{array}$ & 0.2828 & 0.014 & 0.105 & 0.480 & 0.328 & 0.073 & 75.12 \\
\hline $\begin{array}{c}\text { Customer complaint } \\
\text { Customer loyalty }\end{array}$ & 0.1611 & 0.021 & 0.219 & 0.457 & 0.209 & 0.094 & 72.04 \\
\hline Overall condition & 0.021 & 0.164 & 0.506 & 0.276 & 0.033 & 72.04 \\
\hline
\end{tabular}

(4) analysis of the evaluation results

In General, assessment result of the third-party logistics enterprise's customer satisfaction is 76.49 points, reached a relatively good level of satisfaction. In addition, factors that influence customer satisfaction of third-party logistics can be accurately sorted, to find out the weak links and guide the next steps. As can be seen from the table, the score of logistics service quality, customer complaints, customer loyalty are lower than overall customer satisfaction scores, so these three was the main factor influence the third-party logistics enterprise's customer satisfaction leve. So we can build sophisticated logistics management information system, take use of advanced logistics management equipment, establish and improve the customers' complaint management system and other ways to improve service quality and customer loyalty, enable enterprises to better and faster development.

\section{Summary}

Third-party logistics company as the most active force in today's logistics industry, is developing rapidly with unprecedented speed. But at the same time, it faces fierce competition, enterprises must improve the quality of services and customer satisfaction. Research on customer satisfaction, to identify its weaknesses in service, and take corresponding measures to improve customer satisfaction and loyalty. Based on reading and referencing large number of relevant literature, combined with third-party popular development and third-party logistics enterprise's own characteristics, set up third-party logistics customer satisfaction evaluation model and its target system.Through the analysis of the evaluation results, put forward a number of improvement measures to improve customer satisfaction.

\section{References}

[1] John T Mentzer, Roger Gomes, Robert E Krapfel. Physical distribution service:A fundament at marketing concept[J].Journal of the Academy of MarketingScience,2012,17(1):53-62.

[2] John T Mentzer,Lisa R Williams. The role of logistics lever agein marketing strategy[J].Journal of Marketing,2011,(8):29-47.

[3] Qiuxiang Yi;Aifeng Yang.Study of affecting factors of the third party logistics satisfaction based 
on PCA[A].Grey Systems and Intelligent Services (GSIS), 2015 IEEE International Conference on[C],2015

[4] Anil Jindal;Kuldip Singh Sangwan.Evaluation of collection methods in reverse logistics by using fuzzy mathematics[J].Benchmarking: An International Journal,2013,No.3

[5] Chen-no Wang.The Study on the Relationship between Third Party Logistic Providers Services and Customers Satisfaction[D].National Taiwan University of Science and Technology,2010

[6] Socrates J. Moschuris;George F. Velis.Customer Perceptions on Service Satisfaction with Third Party Logistics (3PL) Service[J].International Journal of Applied Logistics,2012,No.4

[7] Chen, FL.An Empirical Analysis on the Effect of the Customers Perception of Service Quality on Customer Satisfaction for the Third-Party Logistics[A].International Conference on Management Innovation and Public Policy (ICMIPP)[C],2012

[8] Huimin Xiao.Customer Satisfaction Evaluation of Third Party Logistics based on Extension Engineering[A].The Ninth International Conference on Information and Management Sciences[C],2010

[9] Sharif, Amir M.;Irani, Zahir;Love, Peter E.D.;Kamal, Muhammad M..Evaluating reverse third-party logistics operations using a semi-fuzzy approach.[J].International Journal of Production Research,2012,No.9 